\title{
Impact and flexural properties of flax fabrics and Lyocell fiber-reinforced bio-based thermoset
}

\author{
Kayode Adekunle', Sung-Woo Cho', Christian Patzelt' \\ Thomas Blomfeldt ${ }^{3}$ and Mikael Skrifvars'
}

\begin{abstract}
A bio-based thermoset resin was reinforced with flax fabrics and Lyocell fiber. The effect of different weave architectures was studied with four flax fabrics with different architectures: plain, twill (two different types), and dobby. The effect of the outer ply thickness was studied and characterized with flexural and impact testing. Composites manufactured with plain weave reinforcement had the best mechanical properties. The tensile strength, tensile modulus, flexural strength, flexural modulus, and impact strength were $280 \mathrm{MPa}, 32 \mathrm{GPa}, 250 \mathrm{MPa}, 25 \mathrm{GPa}$, and $75 \mathrm{~kJ} / \mathrm{m}^{2}$, respectively. Reinforcements with twill-weave architecture did not impart appreciable flexural strength or flexural modulus even when the outer thickness was increased. Plain- and dobby (basket woven style)-weave architectures gave better reinforcing effects and the flexural properties increased with an increase in outer thickness. Water absorption properties of the composites were studied and it was observed that the hybridization with Lyocell fiber reduced the water uptake. Fieldemission scanning electron microscopy was used to study the micro-structural properties of the composites.
\end{abstract}

\section{Keywords}

water absorption, impact test, Lyocell fiber, flax fiber, bio-based resin

\section{Introduction}

For environmental and economic considerations, there have been intense research studies in developing new, lighter weight, higher strength, and more environmentfriendly materials without compromising safety but at lower cost and better controlled manufacturing methods. Weight reduction improves fuel economy and utilizing the materials from renewable resources, leading to cut in emissions.

Natural fiber-reinforced composites have been studied by many authors, and natural fibers such as flax, jute, bamboo, sisal, hemp, ramie, abaca, kapok, etc., are of particular interest as reinforcement in structural composites. However, the shortcomings of these natural fibers cannot be overlooked if they are to replace the man-made glass fibers. Moisture uptake, ${ }^{1}$ inadequate fiber/matrix adhesion ${ }^{2}$ as a result of poor compatibility with the hydrophobic matrix, low thermal stability, lack of uniformity of properties due to climatic conditions when cultivated, decortications, etc., make natural fibers less attractive in composite manufacturing. ${ }^{3}$

These shortcomings have been overcome by pretreatment of the fibers which will modify the fiber surface and reduce the moisture absorption and increase the surface roughness for better fiber-matrix adhesion, consequently leading to composites with good

\footnotetext{
'School of Engineering, University of Borås, Borås, Sweden.

${ }^{2}$ Automotive Engineering, Westsächsische Hochschule Zwickau, University of Applied Sciences, Zwickau, Germany.

${ }^{3}$ Department of Fibre and Polymer Technology, School of Chemical Science and Engineering, Royal Institute of Technology, Stockholm, Sweden.
}

Corresponding author:

Kayode Adekunle, School of Engineering, University of Borås, SE-50I 90 Borås, Sweden

Email: kayode.adekunle@hb.se 
mechanical properties. ${ }^{4-6}$ Mwaikambo et al. ${ }^{6}$ did comprehensive studies on fiber alkalization and found that alkalization modifies the plant fibers and it promotes the development of fiber-resin adhesion, which will result in increased interfacial energy and, hence improvement in the mechanical and thermal stability of the composites. Stuart et al. ${ }^{7}$ explored the use of enzymes, chelators, and enzyme/chelator systems as an environment-friendly means of improving the quality of flax fiber for composite applications.

Natural fibers have been found to have extensive applications in building and civil engineering fields. ${ }^{4}$ Flax fibers possess moderately high specific strength and stiffness compared to other natural fibers and the properties of flax fiber are controlled by the fine molecular structure of the fiber which is affected by growing conditions and the fiber processing techniques used., ${ }^{4,8}$ Variation in natural fiber properties depending on cultivation, location, or on climate has been a major problem to composite manufacturers as compared to glass and carbon fibers which have well-defined manufacturing processes and techniques.

Peponi et al. ${ }^{9}$ also stressed the inconsistency of natural fiber properties even within the same plant. However, the desirable properties for fibers include excellent tensile strength and modulus, high durability, low bulk density, good moldability, and recyclability. ${ }^{10}$ A variety of bio-based composites has been produced based on renewable polymers and their properties characterized. ${ }^{11-13}$

Despite all research efforts, the challenge is still to replace conventional glass-reinforced composites with completely bio-based composites that exhibit acceptable mechanical and thermal properties, good structural and functional stabilities during storage use, and yet susceptible to environmental degradation upon disposal. ${ }^{14}$

Hybridization is combining dissimilar materials to bring together the best of both materials. The end result is a product with superior properties which could not be achieved by the individual component. The term hybrid refers to the end product of the hybridization and in this study, the type of hybrid composites prepared is referred to as sandwich hybrids, also known as core-shell, in which one material is sandwiched between two layers of another.

In this study, flax fabrics and carded Lyocell fiber were used to reinforce unmodified acrylated epoxidized soybean oil (AESO) and the effect of the outer ply thickness was examined. The reinforcement with plain-weave architecture had the highest mechanical properties whereas the hybridization with Lyocell fiber reduced the water absorption by the composite. The aim was to manufacture a flax/Lyocell hybrid composite with better mechanical properties and at the same time has low-water absorption characteristics than composites reinforced with only flax fibers. Fiber type A hybridized with Lyocell fiber gave the best flexural properties and this type of composite can be used in load or weight-support applications.

\section{Experimental}

\section{Materials}

AESO was used as matrix in the composite preparation. The chemical structure of the AESO is shown in Figure 1. The AESO resin is referred to as TRIBEST, and it was supplied by Cognis $\mathrm{GmbH}$, Monheim, Germany. Khot et al. ${ }^{15}$ have also characterized the AESO resin. Four different types of flax-woven fabrics were used as reinforcements in the composite preparation (Table 1 and Figure 2), the fabrics were supplied by Libeco Lagae, Belgium. A Lyocell-staple fiber (Tencel Lenzing Lyocell, $1.7 \mathrm{dtex}, 30 \mathrm{~mm}$ cut length) was supplied by Lenzing AG, Austria. The Lyocell fiber was carded and needled (Figure 3) to get a non-woven mat. The free radical initiator, tert-butyl peroxybenzoate, was supplied by Aldrich Chemical company, Wyoming, IL, USA.

\section{Fiber surface treatment}

The flax fabrics were washed with $4 \%$ sodium hydroxide for $1 \mathrm{~h}$ and later rinsed with distilled water to neutralize the effect of the sodium hydroxide solution. Litmus paper was used frequently to check the neutrality. The fabrics were dried over night at room

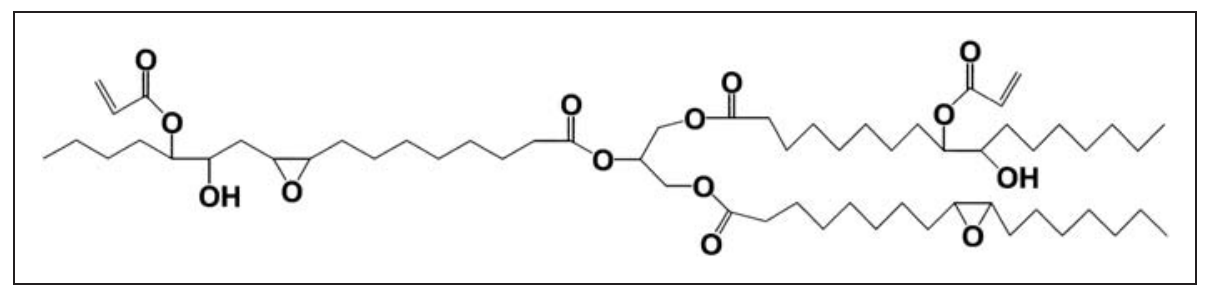

Figure I. Acrylated epoxidized soybean oil. 
Table I. Flax fabric specifications

\begin{tabular}{llllllll}
$\begin{array}{l}\text { Fiber } \\
\text { type }\end{array}$ & Composition & $\begin{array}{l}\text { Warp } \\
\text { (threads/cm) }\end{array}$ & $\begin{array}{l}\text { Yarn number } \\
(\text { tex })\end{array}$ & $\begin{array}{l}\text { Weft } \\
\text { (picks/cm) }\end{array}$ & $\begin{array}{l}\text { Yarn number } \\
\text { (tex) }\end{array}$ & $\begin{array}{l}\text { Surface } \\
\text { weight }\left(\mathrm{g} / \mathrm{m}^{2}\right)\end{array}$ & Weave \\
\hline A & $100 \% \mathrm{Li}$ & 3.4 & 667 & 3 & 27,8 & 250 & Plain \\
B & $100 \% \mathrm{Li}$ & 10 & 104,2 & 10 & 104,2 & 220 & Twill $2 / 2$ \\
C & $100 \% \mathrm{Li}$ & 8 & 263 & 8 & 263 & 430 & Twill 2/2 \\
D & $52 \% \mathrm{Li} / 48 \%$ basalt & $16.8 / 1.67$ & $42 / 380$ & $16.8 / 1.69$ & $42 / 380$ & 285 & Dobby \\
\hline
\end{tabular}

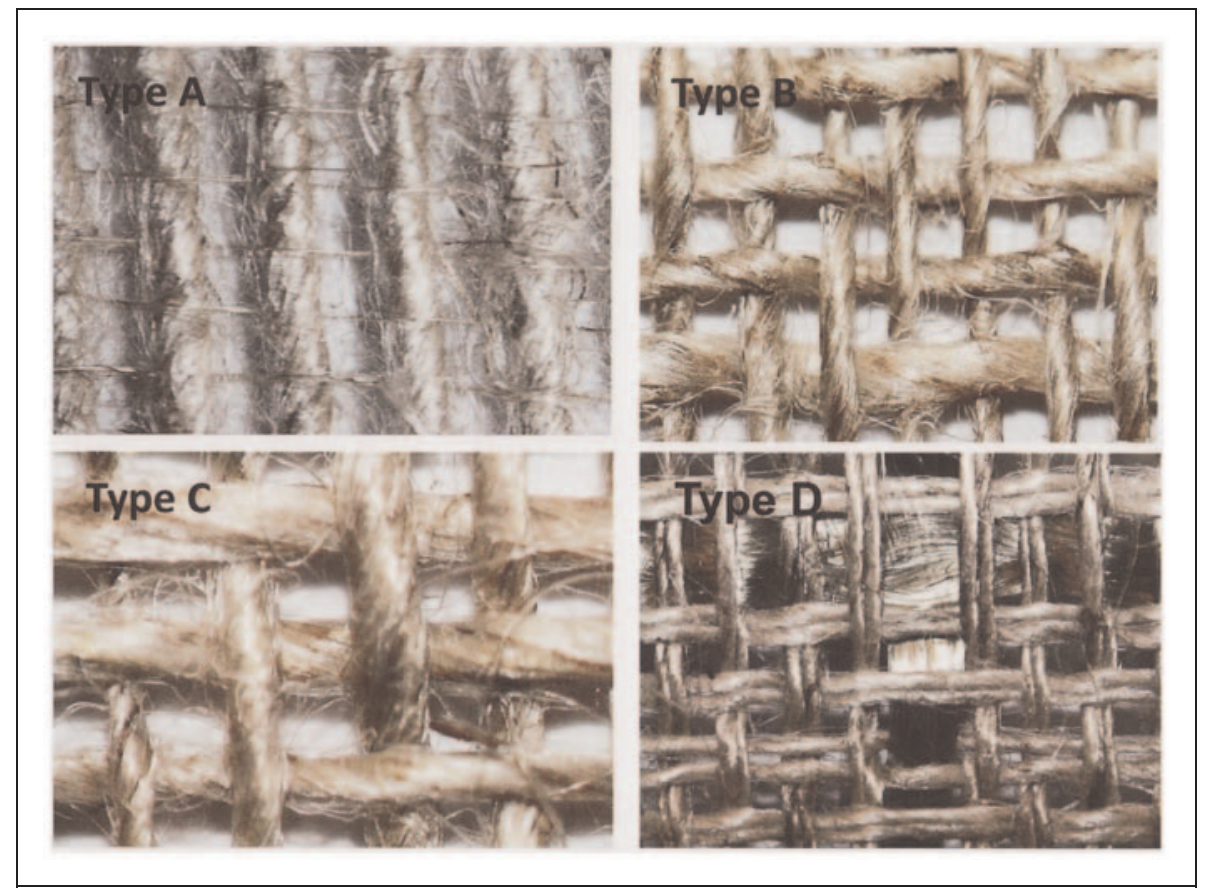

Figure 2. Flax fabric reinforcements (fiber types A, B, C, and D).

temperature and post-treated by drying for about $1 \mathrm{~h}$ in an oven at a temperature of about $105^{\circ} \mathrm{C}$. The fabrics were then ironed with an electric iron to align the misaligned fiber which occurred during washing. The Lyocell fibers were not washed; they were used as obtained from the needling machine.

\section{Composite preparations}

AESO was used as matrix and blended with $2 \mathrm{wt} \%$ tert-butyl peroxybenzoate as free radical initiator. Composite laminates were made by first stacking sheets of reinforcements and by resin impregnating each sheet by hand spray. The prepreg was then placed in a metallic mold $\left(20 \times 20 \mathrm{~cm}^{2}\right)$ and compression molded at $160^{\circ} \mathrm{C}$ for $5 \mathrm{~min}$ using a pressure of $40 \mathrm{bar}$. The hybrid composites were made by sandwiching plies of the carded Lyocell fiber mat in between the flax fabrics. The flax-Lyocell ratio was maintained at approximately $60: 40$ by weight and compression molded as explained earlier. The direction of the carding was taken to be the direction of the fiber in the case of the Lyocell fiber, and no specific fiber direction in the case of the flax fabrics due to biaxial woven pattern except for flax fabric type A, which is plain weaved with very thin fiber in the weft direction. This fabric is similar to a unidirectional fabric, as the thin weft reduces the crimp considerably. The hot press was supplied by Rondol Technology Ltd., Staffordshire, UK. The fiber-resin ratio was about $60: 40 \mathrm{wt} \%$ in all cases. The surface weight of flax fabric reinforcements and the weave architecture are given in Table 1.

The hybrid composites were designated as follows: $\left[\mathrm{A}_{1} \mathrm{~L}_{1}\right]_{\mathrm{s}},\left[\mathrm{A}_{2} \mathrm{~L}_{1}\right]_{\mathrm{s}},\left[\mathrm{B}_{1} \mathrm{~L}_{1}\right]_{\mathrm{s}},\left[\mathrm{B}_{2} \mathrm{~L}_{1}\right]_{\mathrm{s}}$, etc. The different letters in the brackets correspond to the various fiber types such as types A, B, C, and D, and Lyocell fiber mat was denoted as $\mathrm{L}$. The subscript digits show the number of plies, and the subscript 's' outside the brackets indicates symmetry about the midplane (e.g., $\left[\mathrm{A}_{2} \mathrm{~L}_{1}\right]_{\mathrm{s}}$ is the sample consisting of four plies of fiber type $\mathrm{A}$ and 


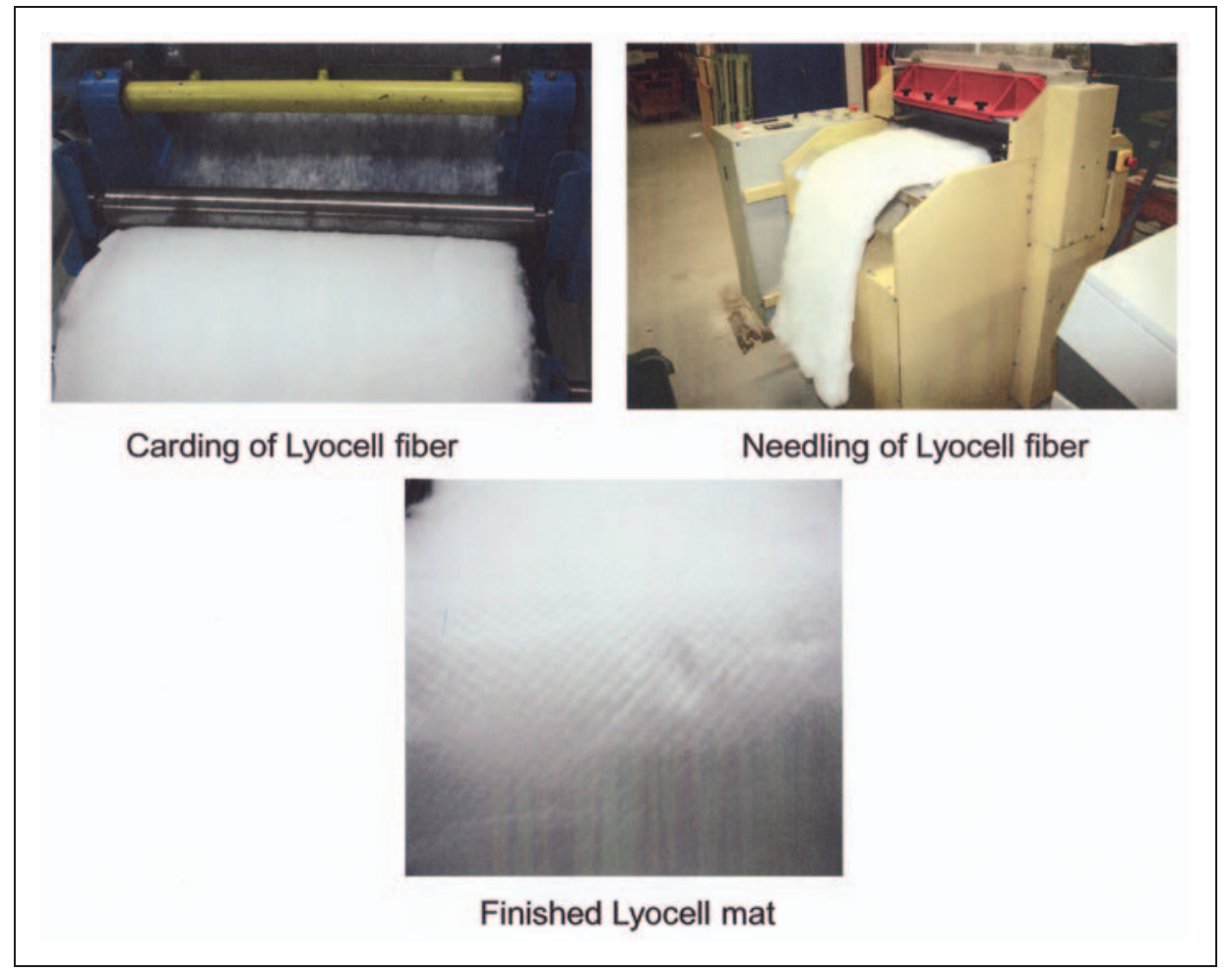

Figure 3. Carding and needling of Lyocell fiber to achieve a non-woven fiber mat.

two plies of Lyocell fiber mats, and the lay-up is $[\mathrm{A} / \mathrm{A} /$ $\mathrm{L} / \mathrm{L} / \mathrm{A} / \mathrm{A}])$. The thickness of the composites was approximately $2.2 \mathrm{~mm}$, whereas the thickness of the hybrid composites was between 2 and $3 \mathrm{~mm}$ depending on the number of outer plies.

\section{Mechanical testing}

The cutting of all specimens was done with laser-cutting machine in order to get high-quality test specimens. The laser machine was of model Laserpro Spirit, 50-W sealed $\mathrm{CO}_{2}$, DC Servo control, and work area of $860 \times 460 \mathrm{~mm}^{2}$. The Lyocell composite specimens were all cut in the carding direction and composite type A was cut in the thicker yarn direction.

The tensile testing was performed according to ISO 527 standard test method for fiber-reinforced plastic composites with a universal $\mathrm{H} 10 \mathrm{KT}$ testing machine (maximum capacity $10 \mathrm{kN}$ ) supplied by Tinius Olsen Ltd., Salfords, UK. Ten specimens were analyzed for each composite laminate.

The flexural testing was performed according to ISO 14125 , with the same testing machine. At least seven specimens were tested for every material.

Impact testing was done on the composite laminates to determine the Charpy impact strength of the unnotched specimens which was evaluated in accordance with ISO 179 using a Zwick test instrument. A total of 10 specimens were tested to determine the mean impact resistance. The samples were tested flatwise.

\section{Field-emission scanning electron microscopy}

Cross-sections and fractured surfaces of the composites were examined using a Hitachi S-4800 Field-emission scanning electron microscopy (FE-SEM). Prior to SEM analysis, the test specimens were stored in a Denton vacuum under $0.1 \mathrm{mbar}$ vacuum pressure and then coated for about $60 \mathrm{~s}$ with a gold powder layer using an Agar high-resolution sputter coater (model 208RH), equipped with a gold target/Agar thickness monitor controller. Micrographs at various magnifications were produced with the video capture computer program InterVideo WinDVR from InterVideo Inc.

\section{Dynamic mechanical thermal analysis}

The time-temperature dependency of the mechanical properties was determined by dynamic mechanical thermal analysis, with a $\mathrm{Q}$ series TA instrument (dual cantilever) supplied by Waters LLC, Newcastle, DE, USA. The dimension of the test specimens was $62 \times 10 \mathrm{~mm}^{2}$, the temperature range was from $30^{\circ} \mathrm{C}$ to $200^{\circ} \mathrm{C}$ and at frequency of $1 \mathrm{~Hz}$. 


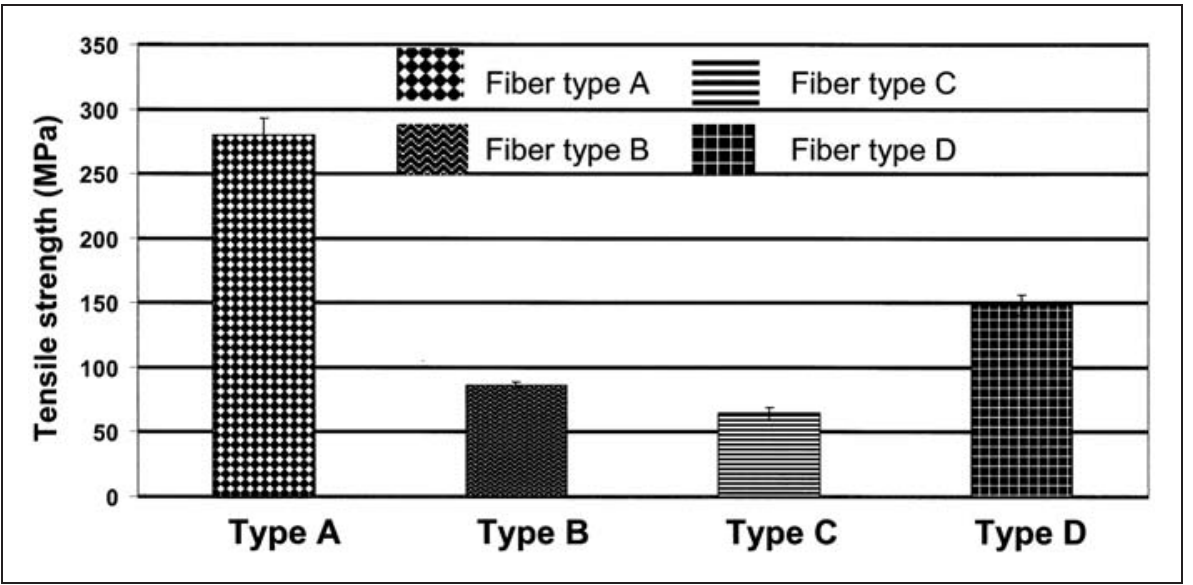

Figure 4. Comparison of tensile strength of the flax fiber-reinforced composites.

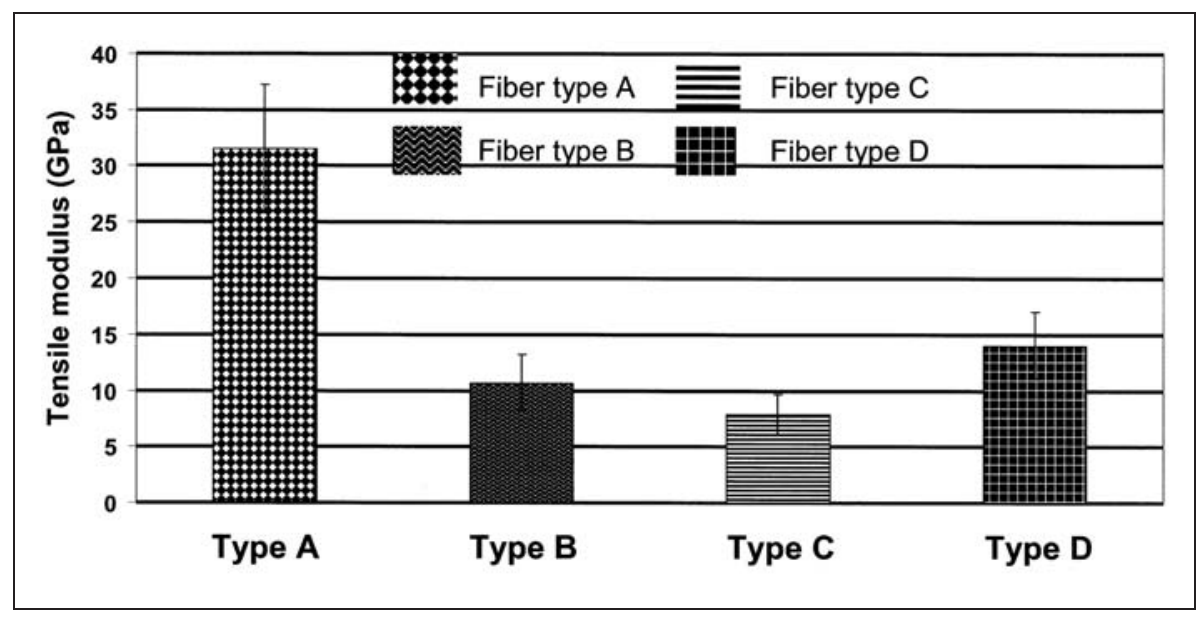

Figure 5. Comparison of tensile modulus of the flax fiber-reinforced composites.

\section{Water absorption of composites}

In order to determine the dimensional stability of the composites, gravimetric water absorption analysis was done on selected composite specimens. The dimensions of the specimens were approximately $36 \times 12 \mathrm{~mm}^{2}$. The specimens were dried overnight for $24 \mathrm{~h}$ at $60^{\circ} \mathrm{C}$ and cooled to room temperature in a dessicator and the weight $\left(w_{\mathrm{o}}\right)$ was taken to the nearest $0.0001 \mathrm{~g}$. The specimens were then immersed in distilled water for $24 \mathrm{~h}$ at room temperature. The water on the surface was wiped away and the weight was taken again $(w)$. Four specimens were analyzed for each of the selected samples and the average was taken. The percentage of water absorption (WA in \%) was calculated using Equation (1):

$$
\mathrm{WA}=\left(w-w_{\mathrm{o}}\right) / w_{\mathrm{o}} \times 100
$$

Here, $w_{\mathrm{o}}$ represents the initial weight after drying and $w$ the weight after water immersion.

\section{Results and discussion}

\section{Mechanical properties}

Figures 4-7 show the tensile and flexural properties of the flax-reinforced composites. Compared to the neat AESO resin with a tensile strength of approximately $6 \mathrm{MPa}$, and a modulus of approximately $440 \mathrm{MPa}$, much better tensile properties were achieved, as expected. The difference between the composites was the weave architecture of the flax fabrics whereas all other components are the same: equal fiber weight, the same amount of resin, and manufacturing techniques.

Composite type A manufactured with plain weave flax fabrics has superior tensile strength and tensile modulus when compared with composite types B, C, 


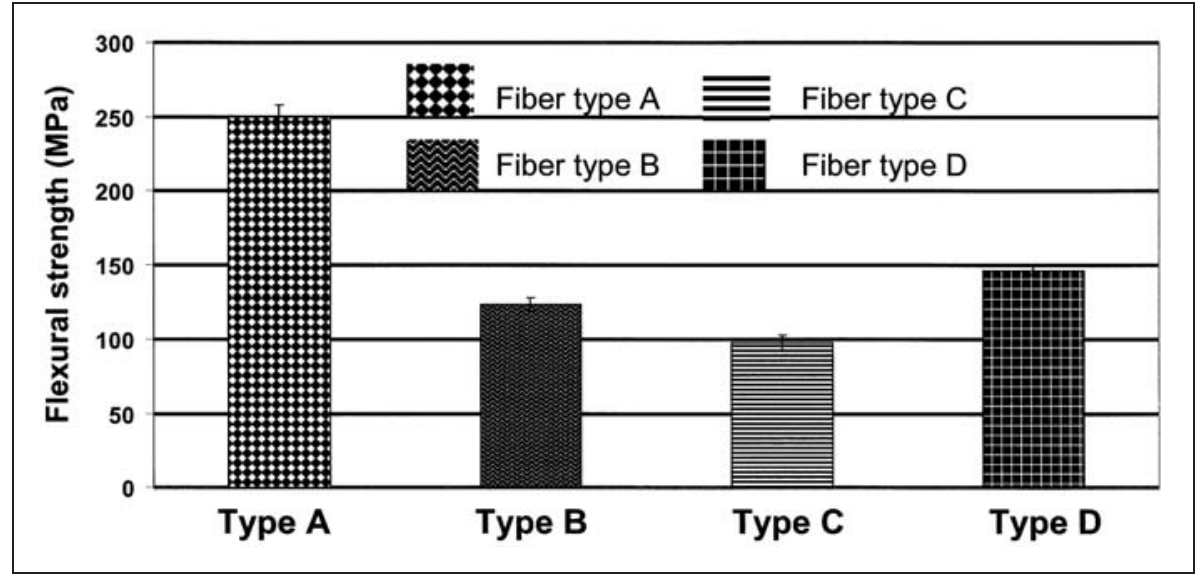

Figure 6. Flexural strength of composite types A, B, C, and D.

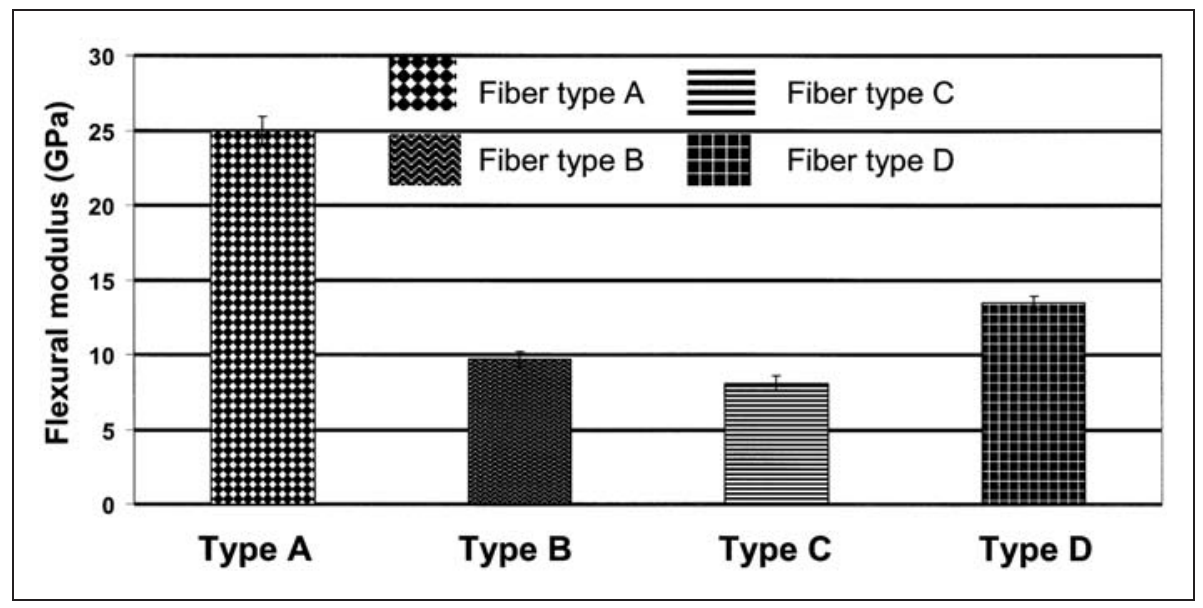

Figure 7. Flexural modulus of composite types A, B, C, and D.

and D manufactured with twill and dobby reinforcements (Figures 4 and 5). The tensile strength of approximately $280 \mathrm{MPa}$ and modulus of about $32 \mathrm{GPa}$ indicated that the composites manufactured with such plain-weave architecture can be used for demanding technical applications. The reinforcement with dobby (basket-woven style) also showed better tensile properties (strength of $149 \mathrm{MPa}$ and modulus $14 \mathrm{GPa}$ ) compared with composites reinforced with twill-weave architecture which had tensile strength of $87 \mathrm{MPa}$ and modulus of $11 \mathrm{GPa}$. The difference between the composite types $\mathrm{B}$ and $\mathrm{C}$ is the density, but the fiber type $\mathrm{B}$ has a lower surface weight and it had better properties compared to the composites prepared with fiber type C.

Figures 6 and 7 show the flexural properties of the flax-reinforced composites. The trend was exactly the same with the tensile properties. Composite type A had superior flexural properties compared to other composites. The flexural strengths of composites A and D were 250 and $146 \mathrm{MPa}$, respectively, and the flexural moduli for composites A and D were 25 and $14 \mathrm{GPa}$, respectively, whereas the flexural properties of composites B and $\mathrm{C}$ were lower compared to composites $\mathrm{A}$ and D.

The impact resistance (Figure 8) shows the same trend as the tensile and flexural properties. Charpy impact method is used to investigate the behavior of specimens under the impact conditions defined and for estimating the brittleness or toughness of specimens within the limitations inherent in the test conditions. The impact resistance of the composite type A was $75 \mathrm{~kJ} / \mathrm{m}^{2}$ whereas the impact resistances for composites $\mathrm{B}, \mathrm{C}$, and $\mathrm{D}$ were 35,36 , and $66 \mathrm{~kJ} / \mathrm{m}^{2}$, respectively.

A preliminary conclusion could be drawn here with respect to the three different mechanical analyses, that the type A composites manufactured with plain-weave architecture fabric have superior mechanical properties compared to the composites manufactured with dobby (basket woven) and twill-weave architecture fabrics. This means that composite type A is the strongest, stiffest, and toughest. It should also be noted that the 


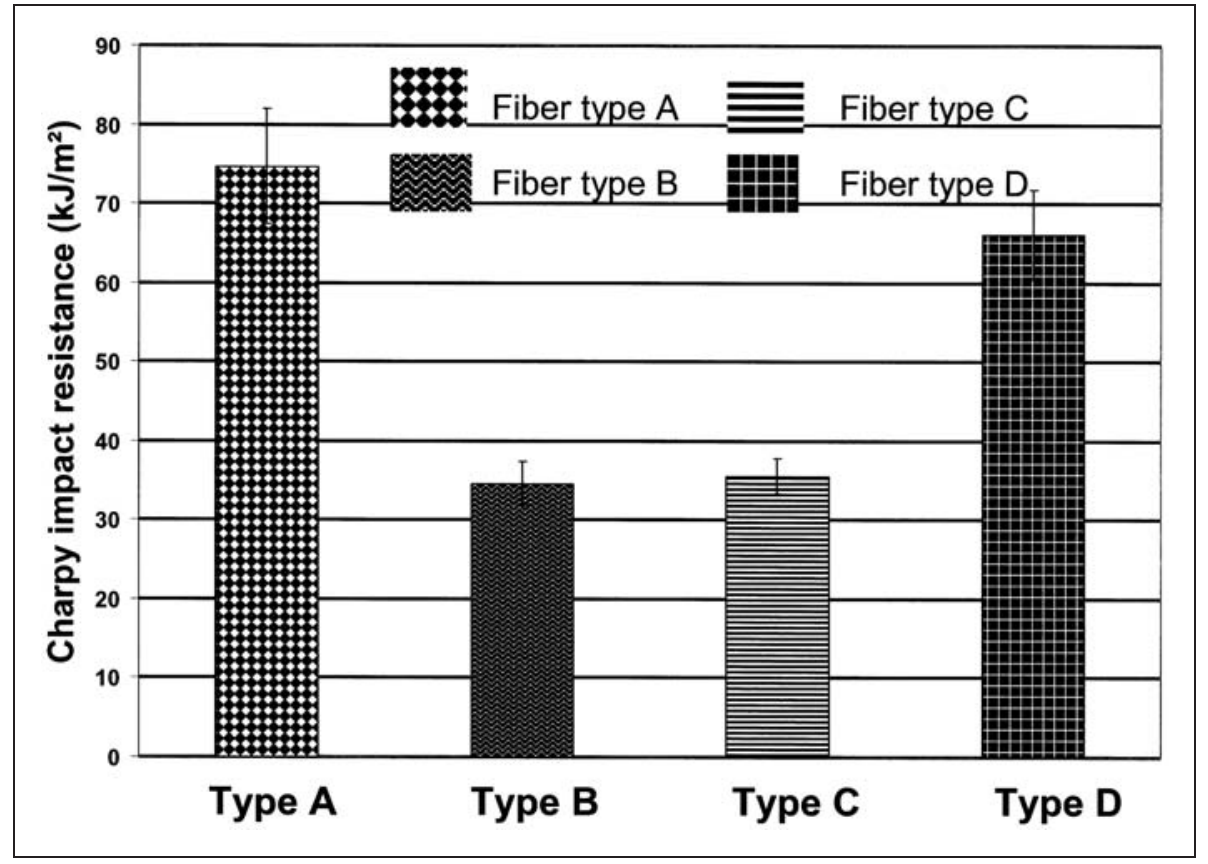

Figure 8. Charpy impact resistance of composites A, B, C, and D.

other reinforcements are biaxial woven but irrespective of this, the plain-woven fiber (type A) showed better properties. The possible explanation for the variation in mechanical properties could be the different weave architectures of the individual fabrics. The composite type A had a plain weave fabric as reinforcement, but this reinforcement is actually more similar to a unidirectional reinforcement, as a very thin weft yarn is used, which reduced the crimp to almost negligible. Therefore, the loading of the composites in the direction of the warp fiber might have contributed to the improved tensile strength and tensile modulus. Composite type $\mathrm{D}$ had relatively better mechanical properties than composite types $\mathrm{B}$ and $\mathrm{C}$, and this was obviously due to the dobby (basket woven)weave type, and the combination of flax and basalt in the fabric type D. Basalt, which is an inorganic fiber, should impart better mechanical properties.

The paragraphs above show the properties of composites manufactured with different fiber reinforcements. Considerably good properties were achieved especially for the type A, which is encouraging regarding the potential use in technical applications. In order to further tailor the properties, hybrid composites were manufactured where a carded Lyocell non-woven was introduced in the lay-up. The interest was to see the effect of the outer ply thickness on the flexural and impact properties of the hybrid composites. Second, to determine the effect of Lyocell reinforcements on the dimensional stability using water absorption analysis. Figure 9 shows the flexural strength of the hybrid composites, 16 different hybrid composites were tested in order to determine their flexural behaviors.

Hybrid composites $\left[\mathrm{A}_{1} \mathrm{~L}_{1}\right]_{\mathrm{s}},\left[\mathrm{A}_{2} \mathrm{~L}_{1}\right]_{\mathrm{s}},\left[\mathrm{A}_{3} \mathrm{~L}_{1}\right]_{\mathrm{s}}$, and $\left[\mathrm{A}_{4} \mathrm{~L}_{1}\right]_{\mathrm{s}}$ (Figure 9) differ in their outer plies from one sheet of flax fabric to four sheets of flax fabric while two layers of Lyocell mat were sandwiched in between the flax fabrics. Composites $\left[\mathrm{A}_{1} \mathrm{~L}_{1}\right]_{\mathrm{s}},\left[\mathrm{A}_{2} \mathrm{~L}_{1}\right]_{\mathrm{s}},\left[\mathrm{A}_{3} \mathrm{~L}_{1}\right]_{\mathrm{s}}$, and $\left[\mathrm{A}_{4} \mathrm{~L}_{1}\right]_{\mathrm{s}}$ showed increase in flexural strength in that order but a critical look at composites $\left[\mathrm{A}_{3} \mathrm{~L}_{1}\right]_{\mathrm{s}}$ and $\left[\mathrm{A}_{4} \mathrm{~L}_{1}\right]_{\mathrm{s}}$ indicated that no significant increase was achieved beyond a specific outer ply thickness. Composites $\left[\mathrm{B}_{1} \mathrm{~L}_{1}\right]_{\mathrm{s}},\left[\mathrm{B}_{2} \mathrm{~L}_{1}\right]_{\mathrm{s}},\left[\mathrm{B}_{3} \mathrm{~L}_{1}\right]_{\mathrm{s}}$, and $\left[\mathrm{B}_{4} \mathrm{~L}_{1}\right]_{\mathrm{s}}$ had increased outer thickness in that order, but this had no effect on the flexural properties, as observed in hybrid composite type A. Similar observation was made in composites $\left[\mathrm{C}_{1} \mathrm{~L}_{1}\right]_{\mathrm{s}}, \quad\left[\mathrm{C}_{2} \mathrm{~L}_{1}\right]_{\mathrm{s}}, \quad\left[\mathrm{C}_{3} \mathrm{~L}_{1}\right]_{\mathrm{s}}$, and $\left[\mathrm{C}_{4} \mathrm{~L}_{1}\right]_{\mathrm{s}}$, which was expected due to the fact that reinforcements (Types B and C) are similar (biaxial, twillweave architecture). Composites $\left[\mathrm{D}_{1} \mathrm{~L}_{1}\right]_{\mathrm{s}}, \quad\left[\mathrm{D}_{2} \mathrm{~L}_{1}\right]_{\mathrm{s}}$, $\left[\mathrm{D}_{3} \mathrm{~L}_{1}\right]_{\mathrm{s}}$, and $\left[\mathrm{D}_{4} \mathrm{~L}_{1}\right]_{\mathrm{s}}$ showed increase in flexural properties due to increase in outer thickness from 138 to $176 \mathrm{MPa}$.

The flexural modulus of the hybrid composites is presented in Figure 10, the modulus of composites $\left[\mathrm{A}_{1} \mathrm{~L}_{1}\right]_{\mathrm{s}}, \quad\left[\mathrm{A}_{2} \mathrm{~L}_{1}\right]_{\mathrm{s}}, \quad\left[\mathrm{A}_{3} \mathrm{~L}_{1}\right]_{\mathrm{s}}, \quad$ and $\quad\left[\mathrm{A}_{4} \mathrm{~L}_{1}\right]_{\mathrm{s}}$ ultimately increased with the outer thickness from 20 to $28 \mathrm{GPa}$, whereas the modulus of hybrid composites (Types B and C) did not show any appreciable increase in spite of the increase in outer thickness. The hybrid composites (Type D) $\left[\mathrm{D}_{1} \mathrm{~L}_{1}\right]_{\mathrm{s}},\left[\mathrm{D}_{2} \mathrm{~L}_{1}\right]_{\mathrm{s}},\left[\mathrm{D}_{3} \mathrm{~L}_{1}\right]_{\mathrm{s}}$, and $\left[\mathrm{D}_{4} \mathrm{~L}_{1}\right]_{\mathrm{s}}$ showed an increase in flexural modulus from 10 to 


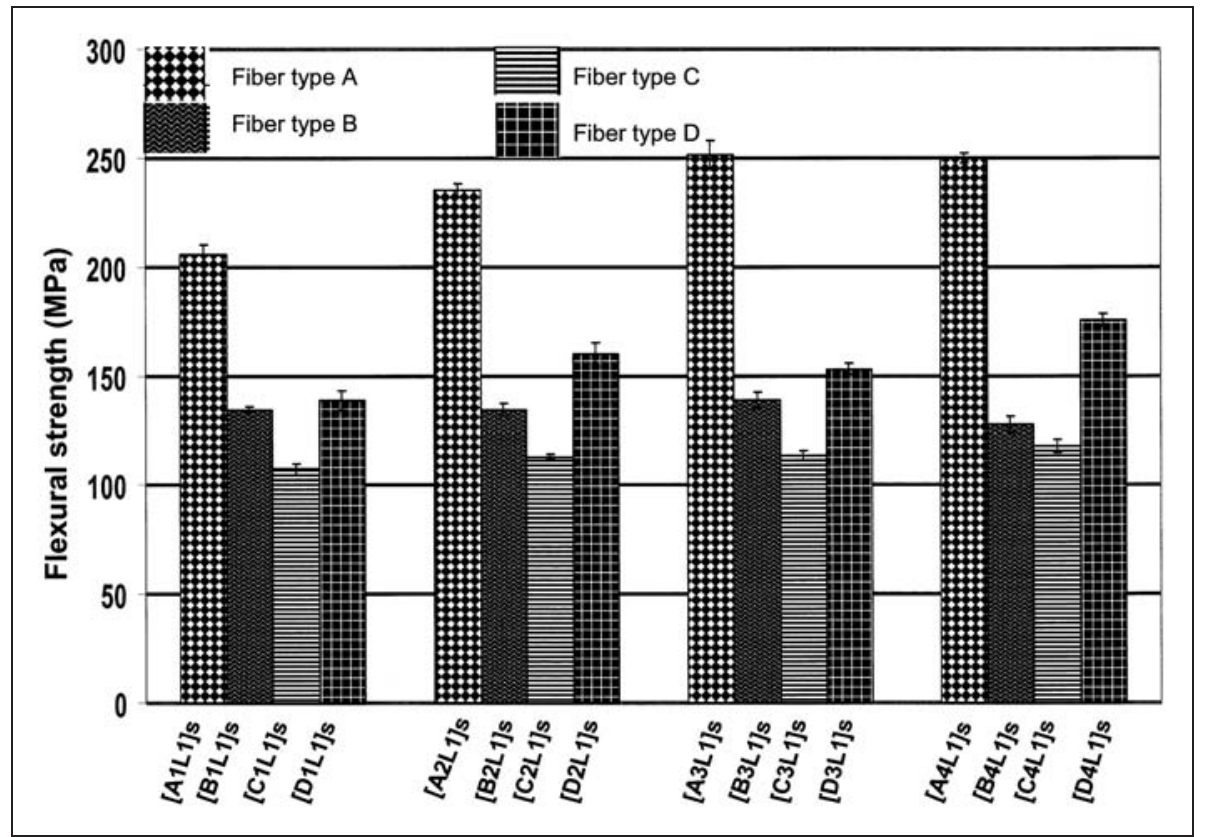

Figure 9. Comparison of the flexural strength of the hybrid composites based on the different outer thicknesses.

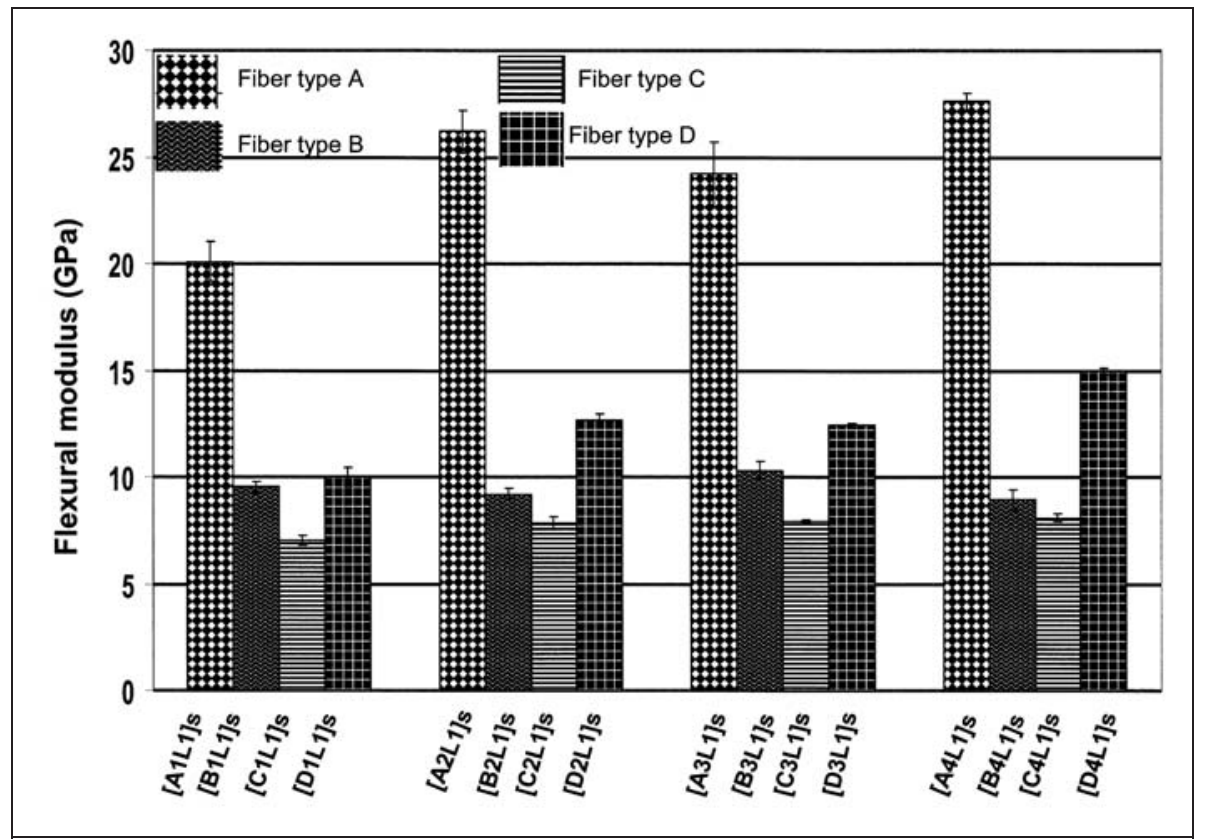

Figure 10. Comparison of the flexural modulus of the hybrid composites based on the different outer thicknesses.

$15 \mathrm{GPa}$. Preliminary conclusion at this stage is that increase in outer thickness may increase the flexural properties of composites but depending on the weave architecture of the reinforcement. Reinforcements with twill-weave architecture did not impart appreciable flexural strength or modulus even when the outer thickness was increased. Plain- and dobby (basket woven style)-weave architectures gave better reinforcing effects and the flexural properties increased with an increase in outer thickness.

The impact properties of the hybrid composites followed a similar trend as obtained in the flexural testing. Hybrid composites $\left[\mathrm{A}_{1} \mathrm{~L}_{1}\right]_{\mathrm{s}}, \quad\left[\mathrm{A}_{2} \mathrm{~L}_{1}\right]_{\mathrm{s}}, \quad\left[\mathrm{A}_{3} \mathrm{~L}_{1}\right]_{\mathrm{s}}$, and $\left[\mathrm{A}_{4} \mathrm{~L}_{1}\right]_{\mathrm{s}}$ increased in impact strength (from 50 to 


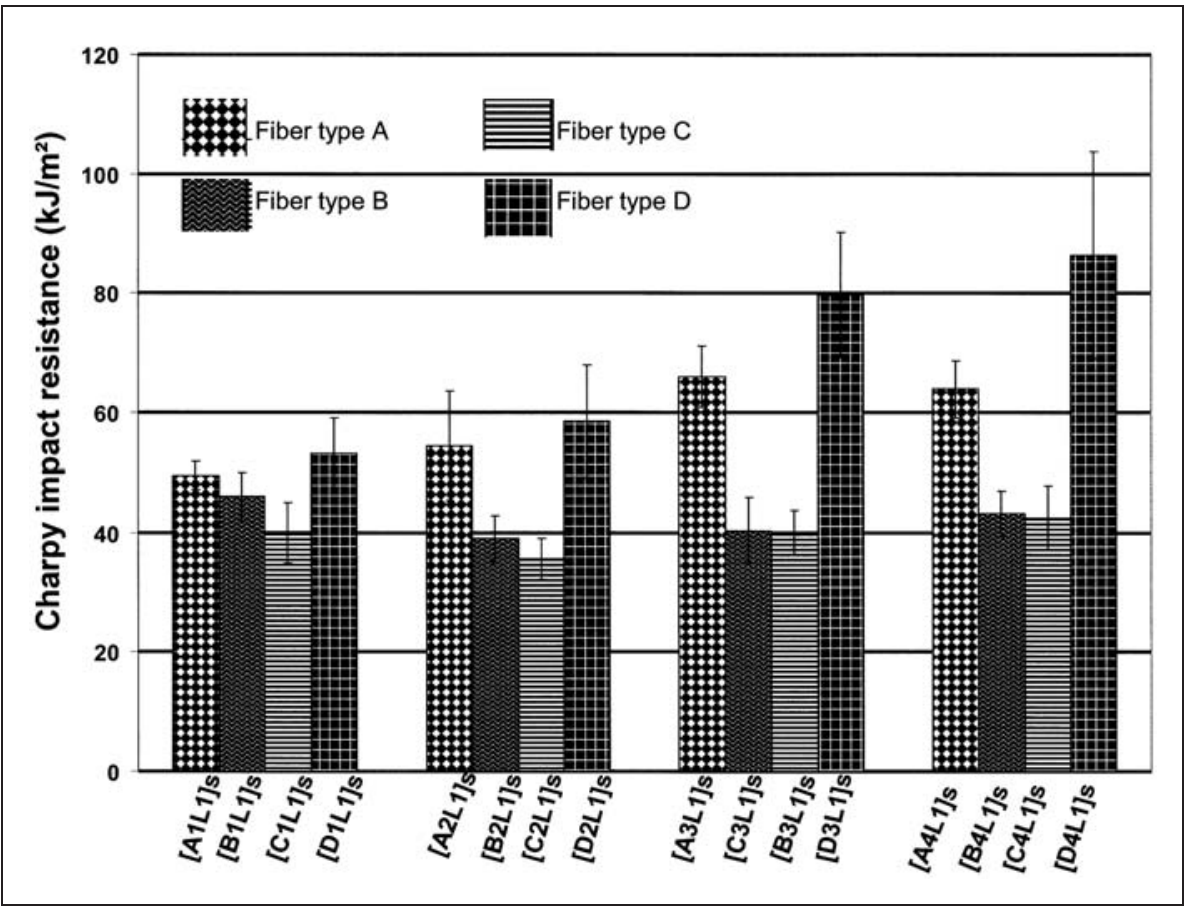

Figure II. Charpy impact resistance of the hybrid composites.

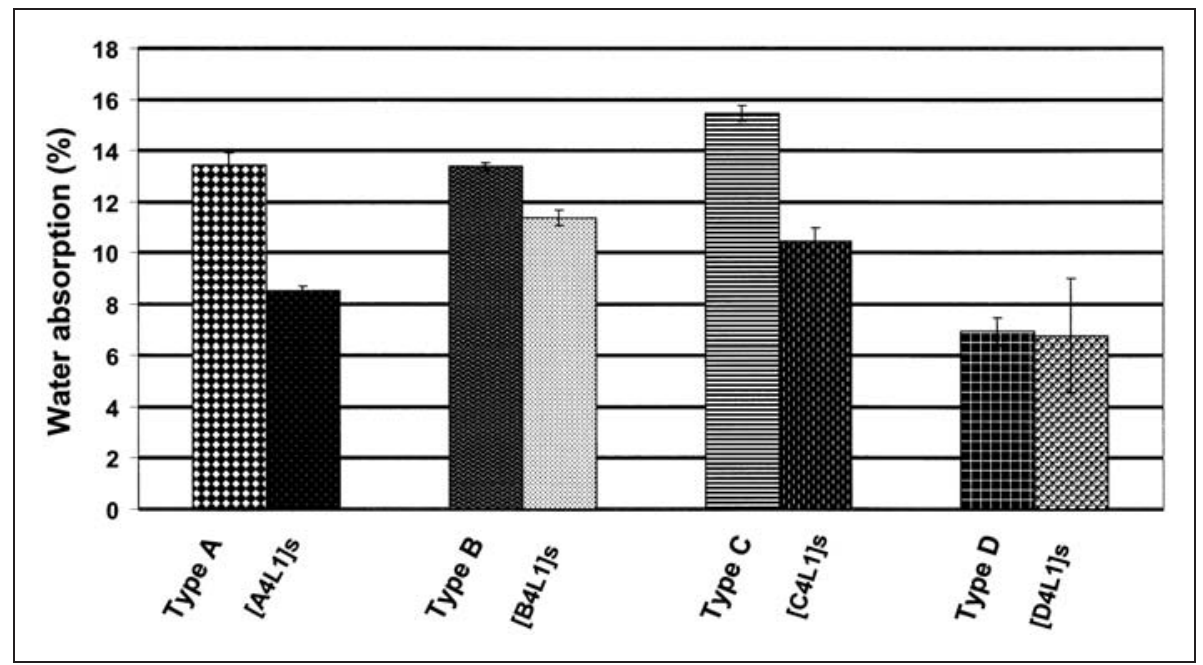

Figure 12. Percentage of water absorption of some selected hybrid composites compared with composite types A, B, C, and D.

$64 \mathrm{~kJ} / \mathrm{m}^{2}$ ) due to the outer thickness of the composites and at a specific limit, an increase in outer thickness did not show further increase in impact properties (Figure 11). This indicated that the impact resistance of a composite can be increased to a certain extent after which increase in outer thickness has no significant effect. The impact strength of hybrid composites, $\left[\mathrm{B}_{1} \mathrm{~L}_{1}\right]_{\mathrm{s}}, \quad\left[\mathrm{B}_{2} \mathrm{~L}_{1}\right]_{\mathrm{s}}, \quad\left[\mathrm{B}_{3} \mathrm{~L}_{1}\right]_{\mathrm{s}}, \quad\left[\mathrm{B}_{4} \mathrm{~L}_{1}\right]_{\mathrm{s}}, \quad\left[\mathrm{C}_{1} \mathrm{~L}_{1}\right]_{\mathrm{s}}, \quad\left[\mathrm{C}_{2} \mathrm{~L}_{1}\right]_{\mathrm{s}}$, $\left[\mathrm{C}_{3} \mathrm{~L}_{1}\right]_{\mathrm{s}}$, and $\left[\mathrm{C}_{4} \mathrm{~L}_{1}\right]_{\mathrm{s}}$ did not increase with the outer thickness. Composites $\left[\mathrm{D}_{1} \mathrm{~L}_{1}\right]_{\mathrm{s}},\left[\mathrm{D}_{2} \mathrm{~L}_{1}\right]_{\mathrm{s}},\left[\mathrm{D}_{3} \mathrm{~L}_{1}\right]_{\mathrm{s}}$, and $\left[\mathrm{D}_{4} \mathrm{~L}_{1}\right]_{\mathrm{s}}$ showed consistent increase in impact strength with increase in outer thickness from 53 to $86 \mathrm{~kJ} / \mathrm{m}^{2}$.

\section{Water absorption}

Selected specimens were analyzed for water-absorption properties (Figure 12). There was a high water absorption in the composites (A, B, C, and D) compared with 


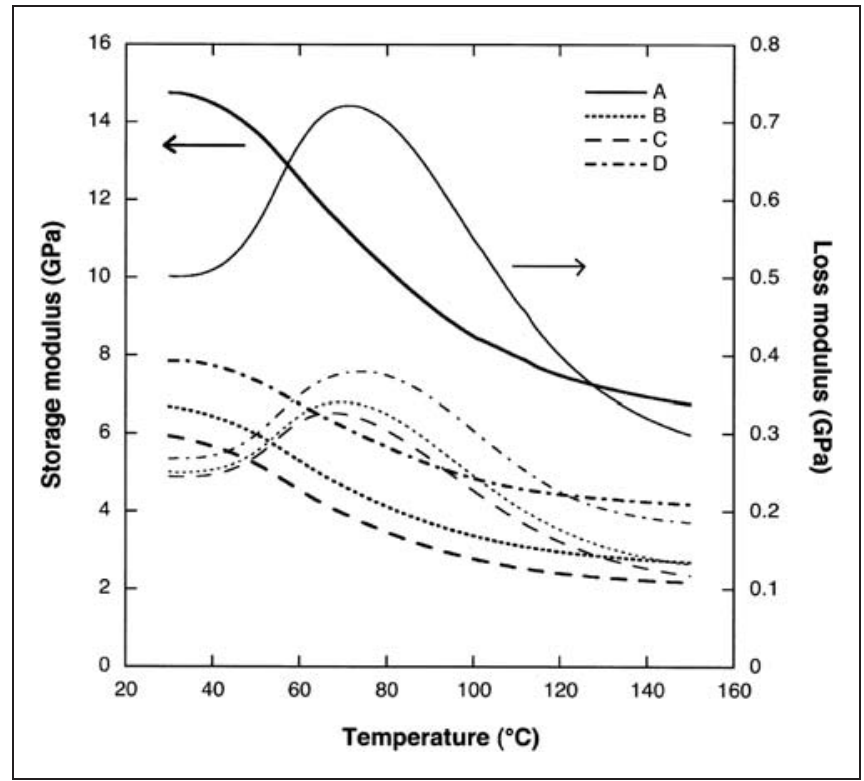

Figure 13. Storage and loss moduli of composite types A, B, C, and D.

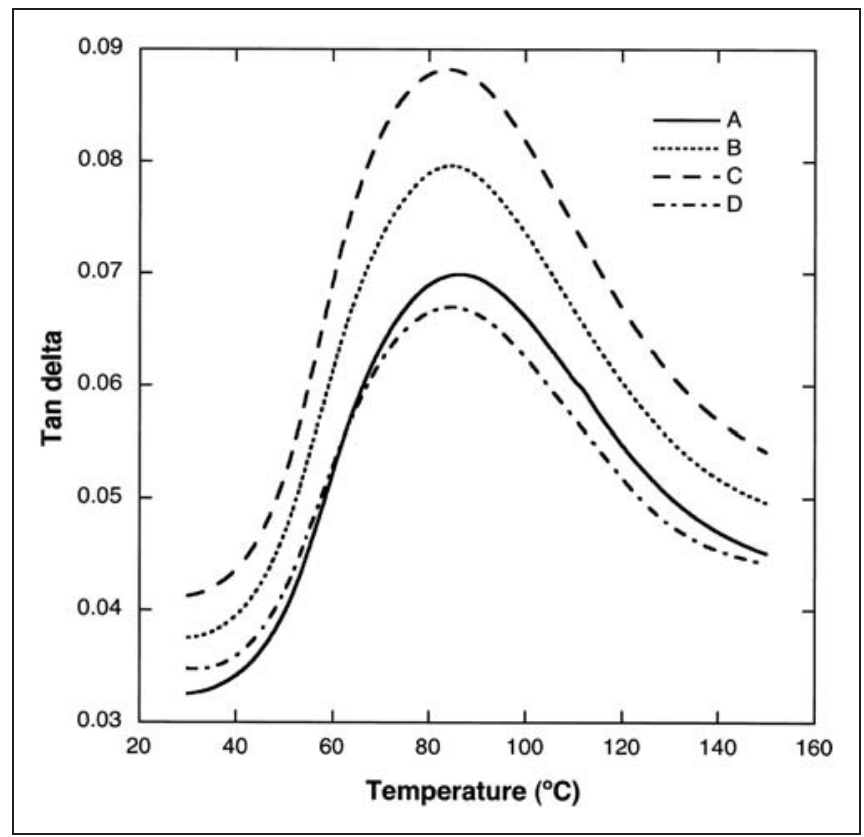

Figure 14. $\operatorname{Tan} \delta$ curve of the flax-reinforced composites.

the hybrid composites. Composite Type D had the lowest water uptake compared to other composites, which was due to the basalt yarn used in the reinforcement. As the fabric is actually containing $48 \mathrm{wt} \%$ basalt, this will reduce the water uptake.

The effect of hybridization with Lyocell fiber had a significant impact because the water absorption was reduced drastically due to the Lyocell fiber. Lyocell fibers are known to have lower water absorption than other natural fibers, due to their high purity, uniformity, controlled morphology, and reproducibility of properties. ${ }^{1,16}$ The water-absorption properties of plant-originated natural fibers limit their use for outdoor applications, but preliminary conclusion here is that the water absorption of natural fiber composites can be reduced to the minimum if higher percentage of Lyocell reinforcement is used as hybrid in natural fiber composites. Surface modification is known to improve 
interfacial adhesion and also reduce water absorption. The Lyocell fiber was used as supplied without any surface modification, however, treatment of the Lyocell fiber could lead to further reduction in water absorption.

\section{Dynamic mechanical thermal properties}

Figure 13 shows the storage and loss moduli of the composites. Composite A had the highest storage modulus $(15 \mathrm{GPa})$ when compared to the other composites. Composite D also had a better storage modulus of $(8 \mathrm{GPa})$ which supported all the results from tensile, flexural, and impact tests, that composites A and D are superior to other composites. The glass transition temperature corresponding to the highest peak in the loss modulus plot was approximately $70^{\circ} \mathrm{C}$ for all composites. Composites $\mathrm{B}$ and $\mathrm{C}$ had comparatively low storage moduli of 7 and $6 \mathrm{GPa}$, respectively. Figure 14 shows the $\tan \delta$ value of the composites and the glass transition temperature corresponding to the maximum peak. On the average, the glass transition temperature for all the composites was approximately $85^{\circ} \mathrm{C}$. The glass transition temperature obtained from the loss modulus curve is usually considered to be more accurate. The ratio of $E^{\prime \prime}$ to $E^{\prime}$ (loss modulus to storage modulus) gives the tangent of the phase angle $\delta$ and $\tan \delta$ is known as the damping and is a measure of energy dissipation. Such parameters provide quantitative information about material behavior.

The storage and loss moduli of some selected hybrid composites are shown in Figure 15. There was a slight reduction in the storage modulus of the hybrid composites which could be due to the effect of Lyocell hybridization. The glass transition temperature measured in the loss modulus curve is approximately $70^{\circ} \mathrm{C}$, whereas the glass transition temperature from the $\tan \delta$ curve (Figure 16) is between $84^{\circ} \mathrm{C}$ and $89^{\circ} \mathrm{C}$.

\section{Field-emission scanning electron microscopy}

Figure 17 shows the scanning electron microscopic images of the tensile-fractured samples. There is a good interfacial adhesion between the fiber and the matrix; instead of fiber pull-out, one could see fiber breakage and broken-end sites on the fractured surfaces which implies that the fiber-matrix interface is intact. Generally, speaking, the mechanical properties of the composites manufactured with the four different flax reinforcements showed acceptable mechanical properties with the tensile strengths and tensile moduli in the range (65-279 MPa) and (8-32 GPa), respectively. Strong interfacial bonding results in short fiber pullout length. Good fiber-matrix adhesion leads to

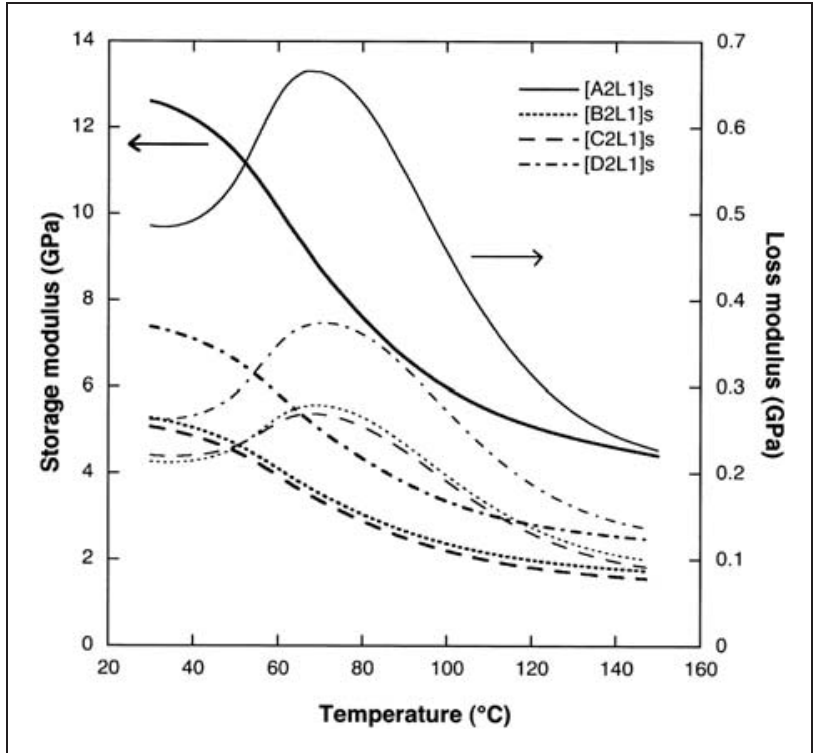

Figure 15. Storage and loss modulus of hybrid composites $\left[A_{2} L_{1}\right]_{s},\left[B_{2} L_{l}\right]_{s},\left[C_{2} L_{1}\right]_{s}$, and $\left[D_{2} L_{1}\right]_{s}$.

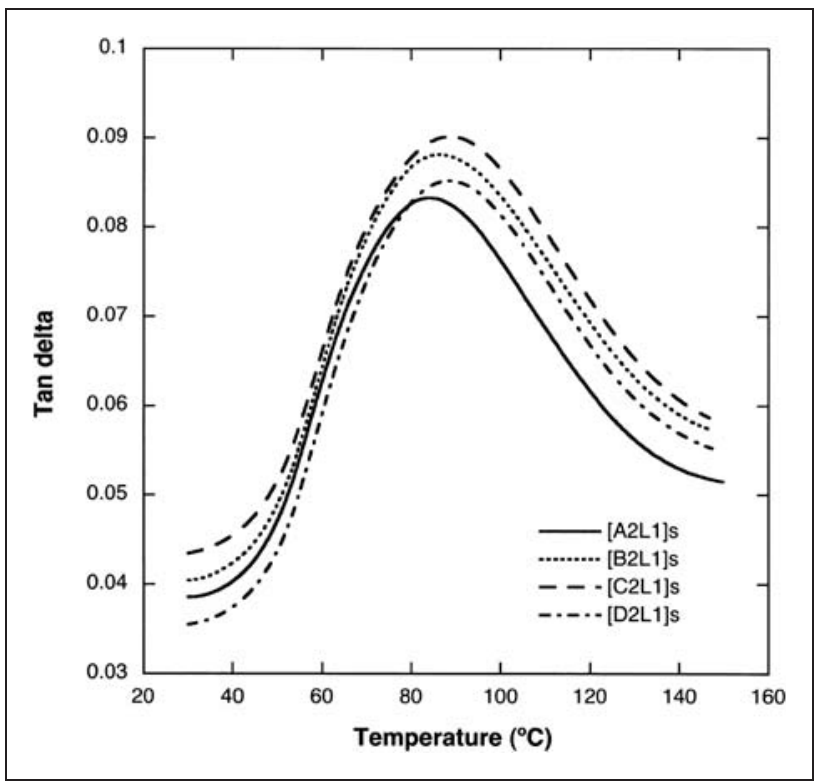

Figure 16. Tan $\delta$ curves of hybrid composites $\left[\mathrm{A}_{2} \mathrm{~L}_{1}\right]_{s},\left[\mathrm{~B}_{2} \mathrm{~L}_{1}\right]_{s}$, $\left[C_{2} L_{1}\right]_{s}$, and $\left[D_{2} L_{1}\right]_{s}$.

higher load to pull-out fiber from the matrix hence good fracture resistance.

Figure 18 is the cross-sectional micrograph of a cut sample (not fractured in the tensile testing). It indicates good compatibility between different layers of flax fabrics but there seems to be a mismatch in the layer between the flax and the Lyocell, and also between the Lyocell layers. A crack, propagated through the 


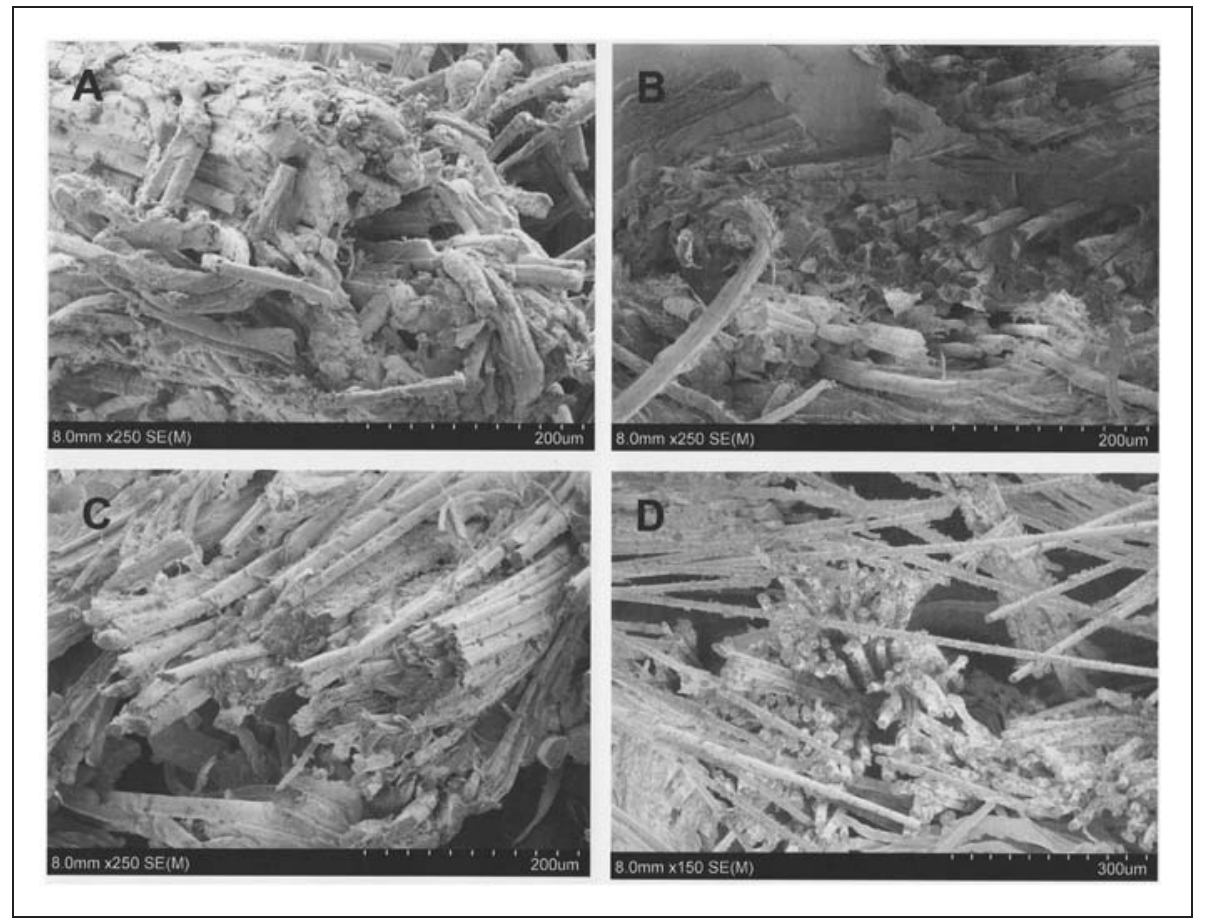

Figure I7. Field-emission scanning electron micrographs of composite types A, B, C, and D.

entire length of the specimen was observed, this could lead to reduction in mechanical properties. Water uptake through the pores could also lower the mechanical properties of the composite. The flax-flax layer shows good compatibility which could be due to flax fiber surface modification.

\section{Conclusions}

An important criterion in determining the properties of textile-reinforced composites is the weave pattern of the reinforcement. Therefore, weaving natural fibers into different textile forms is an important factor in order to tailor their final properties. Compression molding is a popular method engaged in making fiber-reinforced polymer composites due to its extreme flexibility, capable of making a wide variety of shapes.

Composites manufactured with plain-weave architecture had superior mechanical properties compared to dobby (basket woven)- and twill-weave architecture. Composite type A (plain weave) is the strongest, stiffest, and toughest due to higher tensile strength and tensile modulus ( $280 \mathrm{MPa}$ and $32 \mathrm{GPa}$ ), respectively. The flexural strength and flexural modulus of composite type A was $250 \mathrm{MPa}$ and $25 \mathrm{GPa}$, respectively, and the impact resistance was $75 \mathrm{~kJ} / \mathrm{m}^{2}$. The other reinforcements are biaxially woven. However, general conclusions cannot be drawn because in the composites investigated, there are several other parameters which

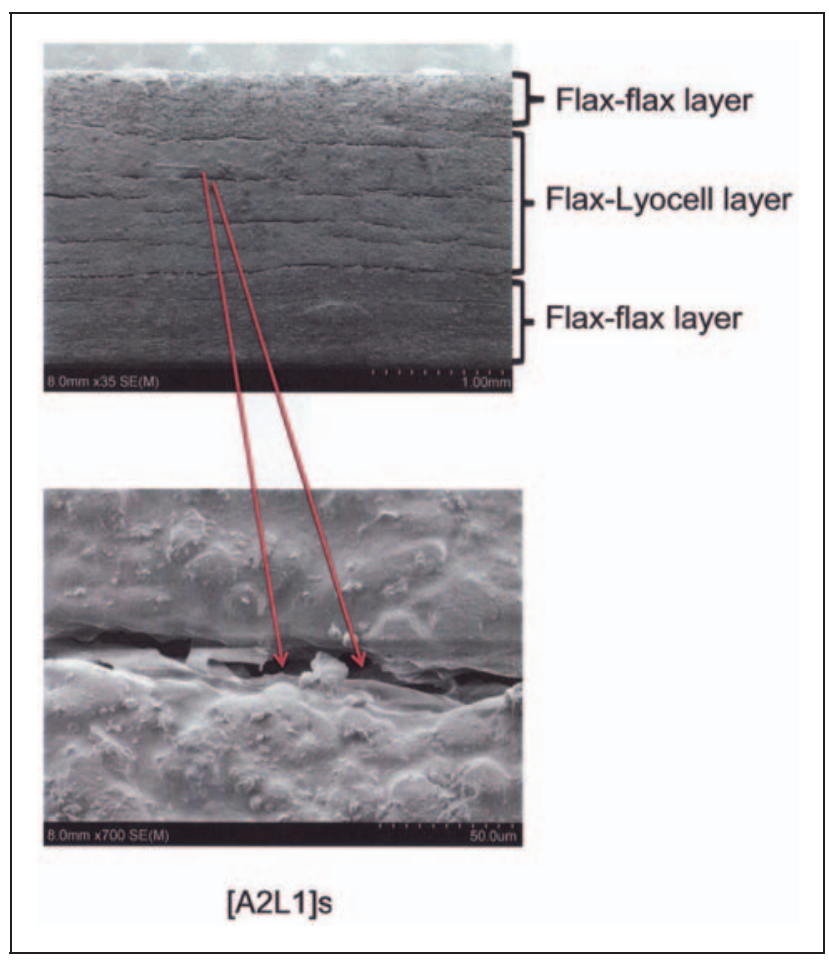

Figure 18. Field-emission scanning electron micrograph of the crack propagation along the cross-section of composite $\left[A_{2} L_{1}\right]_{s}$. 
differ from one laminate to other, not only the weave architecture, for instance, the surface weight and, for the fiber type D, there are two different fibers, flax and basalt. All these factors can surely affect the mechanical properties. The obtained results should therefore be seen as an indicative, regarding the potential to use these fabrics in structural composites.

For the hybrid composites, increase in outer ply thickness may increase the flexural properties of the composites but depending on the weave architecture of the reinforcement. Reinforcements with twill-weave architecture did not impart appreciable flexural strength or flexural modulus even when the outer thickness was increased. Plain- and dobby (basket woven style)-weave architectures gave better reinforcing effects and the flexural properties increased with an increase in outer thickness. Hybrid composites $\left[\mathrm{A}_{1} \mathrm{~L}_{1}\right]_{\mathrm{s}},\left[\mathrm{A}_{2} \mathrm{~L}_{1}\right]_{\mathrm{s}}$, $\left[\mathrm{A}_{3} \mathrm{~L}_{1}\right]_{\mathrm{s}}$, and $\left[\mathrm{A}_{4} \mathrm{~L}_{1}\right]_{\mathrm{s}}$ increased in impact strength from 50 to $64 \mathrm{~kJ} / \mathrm{m}^{2}$ due to the outer thickness of the composites but at a point, an increase in outer thickness did not further improve the impact properties. Composites $\left[D_{1} L_{1}\right]_{s},\left[D_{2} L_{1}\right]_{s},\left[D_{3} L_{1}\right]_{s}$, and $\left[D_{4} L_{1}\right]_{s}$ showed consistent increase in impact strength with increase in outer thickness from 53 to $86 \mathrm{~kJ} / \mathrm{m}^{2}$.

The hybridization with Lyocell fiber had a great impact on the water-absorption properties of the composites, because water uptake reduced drastically when compared to other composites. Lyocell fiber is known to have lower water absorption than other natural fibers.

\section{Acknowledgment}

The authors would like to acknowledge Jan Johansson, Swerea IVF, Mölndal, Sweden, for his assistance with the impact testing.

\section{Funding}

This research received no specific grant from any funding agency in the public, commercial, or not-for-profit sectors.

\section{References}

1. Carrillo F, Colom X and Canavate X. Properties of regenerated cellulose lyocell fiber-reinforced omposites. J Reinf Plast Compos 2010; 29: 359-371.

2. Wang B, Panigrahi S, Tabil L and Crerar W. Pre-treatment of flax fibers for use in rotationally molded biocomposites. J Reinf Plast Compos 2007; 26: 447-463.
3. Van de Velde K and Kiekens P. Thermoplastic pultrusion of natural fiber einforced composites. Comp Struct 2001; 54: 355-360.

4. Kalia S, Kaith B and Kaur I. Pretreatments of natural fibers and their application as reinforcing material in polymer composites-a review. Polym Eng Sci 2009; 49: 1253-1272.

5. Bledzki AK and Gassan J. Composites reinforced with cellulose based fibers. Prog Polym Sci 1999; 24: 221-274.

6. Mwaikambo LY and Ansell MP. Chemical modification of hemp, sisal, jute, and kapok fibers by alkalization. J Appl Pol Sci 2002; 84: 2222-2234.

7. Stuart T, Liu Q, Hughes M, et al. Structural biocomposites from flax- part I: Effect of biotechnical fibre modification on composite properties. Compos Part A 2006; 37: 393-404.

8. Zengshe L, Erhan SZ, Akin DE, et al. Modified flax fibers reinforced soy-based composites: Mechanical properties and water absorption behavior. Compos Interf 2008; 15: 207-220.

9. Peponi L, Biagiotti J, Torre L, et al. Statistical analysis of the mechanical properties of natural fibers and their composite materials. I. natural fibers. Polym Compos 2008; 29: 313-320.

10. Li X, Tabil LG and Panigrahi S. Chemical treatments of natural fiber for use in natural fiber-reinforced composites: A review. Polym Envir 2007; 15: 25-33.

11. Mishra S, Mohanty AK, Drzal LT, et al. A review on pineapple leaf ibers, sisal fibers and their biocomposites. Macromol Mater Eng 2004; 289: 955-974.

12. Liu W, Misra M, Askeland P, et al. Green composites from soy based plastic and pineapple leaf fiber, fabrication and properties evaluation. Polym 2005; 46: 2710-2721.

13. Mohanty AK, Tummala $\mathrm{P}$, Liu W, et al. Injection molded biocomposites from soy protein based bioplastic and short industrial hemp fiber. Polym Envir 2005; 13: 279-285.

14. John MJ, Anandjiwala RD and Thomas S. Hybrid composites (Chapter 12), natural fibre Reinforced polymer composite: Macro to nanoscale. Old City Publishing, 2009, pp.315-328.

15. Khot SN, Lascala JJ, Can E, et al. Development and application of triglyceride-based polymers and composites. J App Pol Sci 2001; 82: 703-723.

16. Fink HP, Weigel P and Purz HJ. Structure formation of regenerated cellulose materials from NMMO-solutions. Prog Polym Sci 2001; 26: 1473-1524. 